\title{
Aus unserer Bibliothek
}

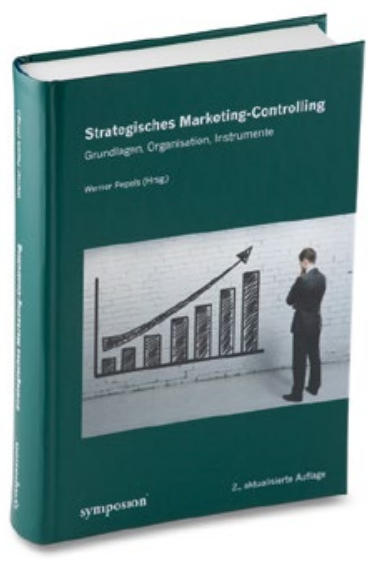

Werner Pepels (Hrsg.)

Strategisches Marketing-Controlling

Symposion Publishing, 2., aktualis. Aufl., Düsseldorf 2013, 451 Seiten, 69 Euro,

ISBN 978-3-86329-441-0

\section{Kernthese}

Scharfer Wettbewerb, verändertes Konsumentenverhalten und der technologische Fortschritt stellen das Marketing von Unternehmen auf den Prüfstand.

\section{Nutzen für die Praxis}

Im Marketing von heute ist herausragendes Management gefordert, das auf immer kürzere Zyklen und knapper werdende Ressourcen reagieren muss. Ein Erfolg ist hier nur mit einem funktionierenden Marketing-Controlling machbar.

\section{Abstract}

Wie kann strategisches Marketing-Controlling angesichts steigender Dynamik und zunehmender Komplexität des Unternehmensgeschehens wirkungsvoll organisiert werden? Das ist die Kernfrage dieses Buches.

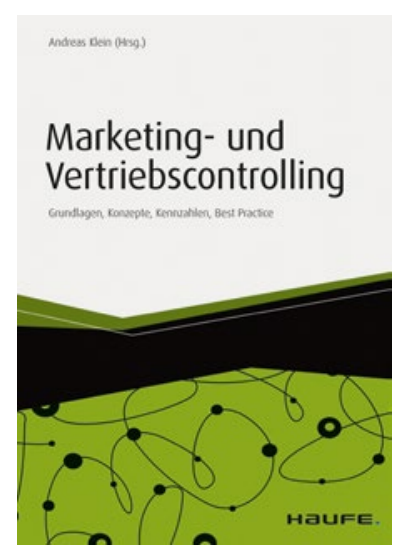

Andreas Klein

Marketing- und Vertriebscontrolling

Grundlagen, Konzepte, Kennzahlen,

Best Practice

Haufe, Freiburg 2014, 280 Seiten, 69 Euro,

ISBN: 978-3-648-05712-4

\section{Kernthese}

Welche Maßnahmen in Marketing und Vertrieb erzeugen die größte Wirkung?

\section{Nutzen für die Praxis}

In diesem Buch stellen Experten Best Practices und Instrumente vor, wie Sie den Erfolg Ihrer Aktionen effizient messen können. Sie zeigen, wie die Wirtschaftlichkeit von Marketingmaßnahmen und von dafür eingesetzten Budgets analysiert wird.

\section{Abstract}

Die Autoren gehen auf aktuelle Erfahrungen zu Themen wie Absatzund Preisplanung, Kunden-DBRechnung und Incentivierung ein. Auch die IT-Praxis wie zum Beispiel der Einsatz von CRM-Systemen und die Suchmaschnenoptimierung werden erklärt.

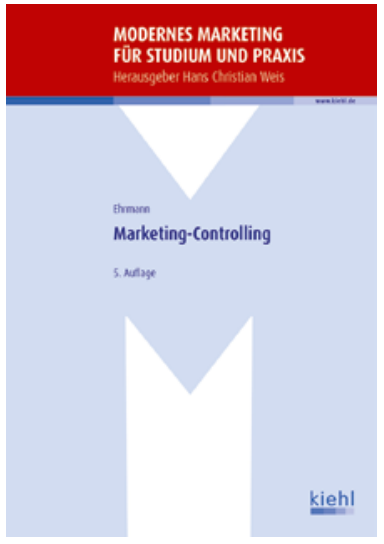

Hans Christian Weis (Hrsg.)

Marketing-Controlling

Reihe: Modernes Marketing für Studium und Praxis, NWB Verlag, 5. Aufl., Herne 2016, 429 Seiten, 32,90 Euro, ISBN 978-3-470-43375-2

\section{Kernthese}

Der effektive und effiziente Einsatz der vorhandenen Mittel ist einer der Erfolgsfaktoren im modernen Marketing.

\section{Nutzen für die Praxis}

Kenntnisse über die Methoden und die Instrumente des Marketing-Controllings sind in Theorie und Praxis unerlässlich. Das bewährte Konzept mit Kontrollfragen und einem umfangreichen Übungsteil machen das Buch zu einem idealen Begleiter in Studium und Weiterbildung.

\section{Abstract}

Diese vollständig überarbeitete Neuauflage gibt einen übersichtlichen und umfangreichen Einblick in die aktuellen Entwicklungen und zeigt die neue Rolle des Marketing-Controllings in der Unternehmenspraxis auf. 